\title{
Identification and safe storage of look-alike, sound- alike medicines in automated dispensing cabinets
}

\author{
Henna Karoliina Ruutiainen (1) 1,2 Miia Marjukka Kallio, 2,3 Sini Karoliina Kuitunen ${ }^{2,3}$
}

\begin{abstract}
- Additional material is published online only. To view, please visit the journal online (http://dx.doi.org/ 10.1136/ejhpharm-2020002531).
\end{abstract}

${ }^{1}$ Faculty of Pharmacy, University of Helsinki, Helsinki, Finland

${ }^{2}$ HUS Pharmacy, HYKS, Helsinki, Uusimaa, Finland ${ }^{3}$ Clinical Pharmacy, Faculty of Pharmacy, University of Helsinki, Helsinki, Finland

\section{Correspondence to} Henna Karoliina Ruutiainen Faculty of Pharmacy, University of Helsinki, Helsinki 00790, Finland; henna.ruutiainen@ helsinki.fi

Received 6 October 2020 Revised 25 November 2020 Accepted 8 December 2020 Published Online First 15 January 2021

EAHP Statement 5: Patien Safety and Quality Assurance.

Check for updates

(C) European Association of Hospital Pharmacists 2021. No commercial re-use. See rights and permissions. Published by BMJ.

To cite: Ruutiainen HK, Kallio MM, Kuitunen SK. Eur J Hosp Pharm

2021:28:e151-e156.

\section{ABSTRACT \\ Objectives Automated dispensing cabinets (ADCs) are} used in hospitals to improve medication safety and decrease costs. However, ADCs do not completely eliminate the risk of mistakes between look-alike, sound-alike (LASA) medicines. The aim of this study was to identify the characteristics of LASA medicines and determine the factors related to their safe storage in ADCs.

Methods The medication selection of one hospital pharmacy's ADC located in an intensive care unit was observed. The study consisted of five parts: a determination of criteria to identify LASA medications, an analysis of an $A D C s^{\prime}$ inventory reports, assessment of the storage of identified LASA medicines, a visual observation of the medicine packages stored in the same storage compartment and qualitative analysis of the medication-use process from prescribing a medicine to removing it from an ADC.

Results Approximately $70 \%(n=355 / 488)$ of the ADCs selection had a LASA risk with at least one product. Moreover, $20 \%$ ( $n=84 / 355)$ of the LASA medicines identified were high-alert medications. Approximately $16 \%(n=58 / 355)$ of the identified LASA medicines were stored unsafely close to at least one other LASA medicine. Less than $4 \%(n=13 / 355)$ of the LASA medicines were unsafely stored high-alert medications. Conclusions $A D C s$ reduce the risks of LASA medication errors when used correctly, but automation can also increase them, for example, when placing multiple LASA medicines in the same storage compartment. Attention should be paid to the identification and safe storage of LASA medicines to promote safe use of ADCs in hospitals.

\section{INTRODUCTION}

In healthcare, most patient safety incidents are caused by medication errors. ${ }^{1}$ Look-alike, soundalike (LASA) medicines can become confused with each other in any step of the medication-use process, exposing patients to incorrect medicine or wrong route errors. ${ }^{2-7}$ LASA names are medicine names that look or sound the same as other medicine names when written or spoken. Look-alike medicine packaging refers to medicine containers or primary packaging that looks like that of another medicine. LASA errors can lead to serious adverse events especially when high-alert medications are involved. ${ }^{8} 9$ High-risk situations arising from LASA naming, similar packaging and labelling could be prevented by ensuring that these are checked thoroughly during prescription, transcription, procurement, storage and dispensing. ${ }^{1479}$

Automated dispensing cabinets (ADCs) are computer-controlled medicine storage and distribution systems, which have been shown to improve medication safety. ${ }^{4}$ 9-11 They represent a decentralised medicine system in which the storage and distribution of medicines take place at the ward. ${ }^{1112}$ ADCs improve medication safety by facilitating the control of medicine consumption through computer-controlled storage and tracing properties, for instance, via a barcode-scanning technology and by preventing the entrance of outsiders into the ADC's dispensary. ${ }^{9-14}$ Furthermore, ADCs bring economic savings due to the increased inventory turn rate reducing the amount of expired expensive medicines and by saving nursing time. ${ }^{11} 15$

When used correctly, ADCs provide a safe storage environment for LASA medicines. ${ }^{911} 12$ ADCs are also an important part of closed-loop medication management systems, where technology is used to support safe medication administration, identify risks of error and document each phase of the medication-use process. ${ }^{9} 111416$ International guidelines promoting the safe storage of LASA medicines have been created, for example, by the Institute of Safe Medication Practices (ISMP). ${ }^{9}$ Even though ADCs have been found to improve medication safety when used correctly, they are also associated with new types of risk, such as mixups between LASA medications. ${ }^{911} 12$ Although LASA medicines have been explored in previous studies (eg, Lebanova et al 2012, Shah et al and Zacher et al 2016), none of them have focused on LASA risks related to ADCs. ${ }^{3717}$ The aim of this study is to identify the characteristics of LASA medications, as well as to determine the factors related to their safe storage in the ADCs.

\section{METHODS}

\section{Study design}

This mixed-methods study consisted of five parts: a determination of criteria to identify LASA medications, an analysis of an ADC's inventory reports to identify LASA names, assessment of the storage of identified LASA medicines, a visual observation of the medicine packages stored in the same storage unit to identify look-alike medicine packaging and a qualitative analysis of the medication-use process from prescribing a medicine to removing it from an ADC to evaluate the potential for confusions. A flowchart of the study is presented in figure 1 . The mixed-methods study followed the SQUIRE 2.0 statement where applicable. ${ }^{18}$

\section{Study setting}

The study was conducted in HUS Pharmacy, the hospital pharmacy at Helsinki University Hospital (HUS) in Finland. Since 2018, HUS Pharmacy has provided an ADC service to wards to reduce costs and time from manual medication distribution and 


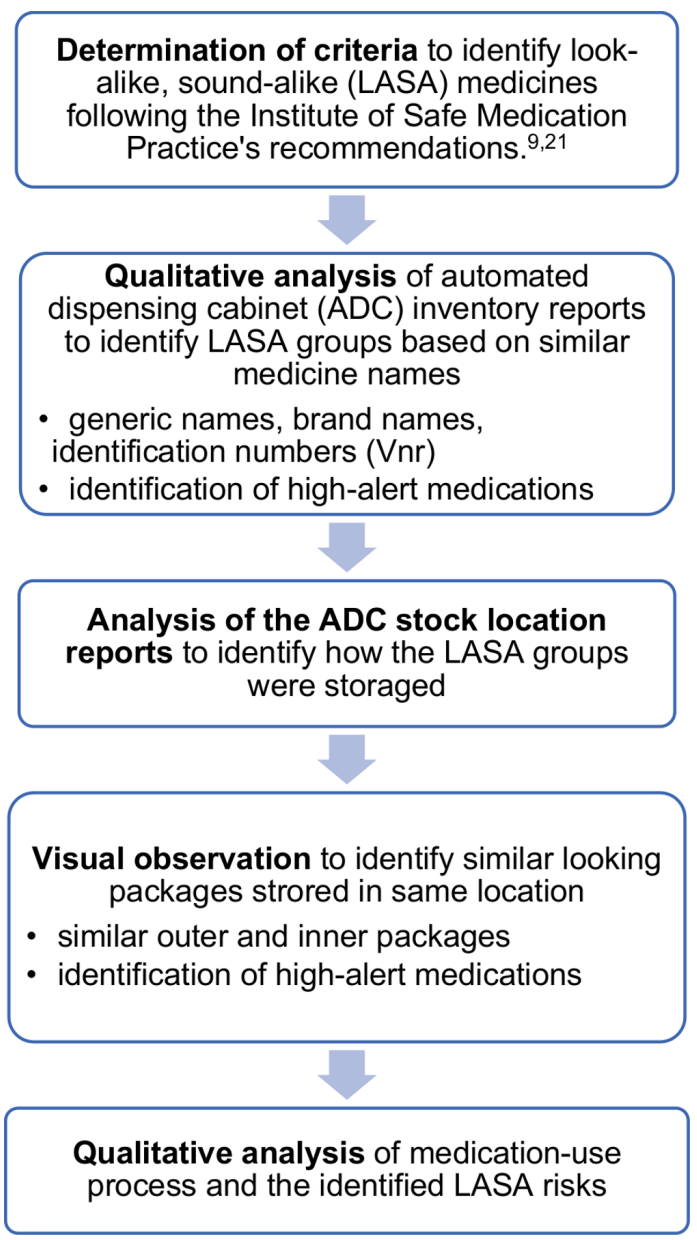

Figure 1 Flowchart of the study.

to reallocate pharmaceutical resources to more clinical work. At the time of the study in February 2020, there was a total of 75 ADCs in HUS.

HUS Pharmacy uses Pyxis MedStation ES ${ }^{\mathrm{TM}}$ ADCs leased from Becton Dickinson Finland Oy. The cabinets can be assembled from different storage units or compartments to meet the varying needs of the wards. Most of the medicines are stored in locked open-access compartments (eg, matrix drawers) that can store up to 90 products. Even though each product is placed individually on a numbered site, the configuration allows the user to remove any product located in the same drawer (eg, another similar-looking package). High-alert medications, such as opioids, can be placed in their own individual secured compartments (locked-lidded CUBIE ${ }^{\mathrm{TM}}$ pockets). ${ }^{9}$

Products are restocked to the ACDs by using the generic or brand name, medicine identification number or bar code, the latest being the most commonly recommended practice. ${ }^{9}$ Medicines identification number, in Finland called the Nordic article number or Vnr number, can also be used in the search. A Vnr number is a six-digit identification code that is mandatory for marketing authorised medicines in the Nordic countries. ${ }^{19}$ Pharmacy technicians are primarily responsible for the restocking and inventorying of the ADCs. At the time of this study, ADCs at HUS were operated using overrides, which means medicines are taken from the ADC without an integrated patient profile..$^{912}$ Medicines are searched and removed from the ADCs using the generic name or brand name of the product, which creates a possibility for mix-ups between two medicines with similar names.

\section{Study method}

The medication selection of one of HUS Pharmacy's ADCs located in an intensive care unit was observed in February 2020 to identify LASA medications. The ADC consisted of a main cabinet with five CUBIE $^{\mathrm{TM}}$ drawers and one matrix drawer, a seven-drawer auxiliary cabinet with seven matrix drawers, one double-column eight-door cabinet, a single-column four-door cabinet and two refrigerators. At the time of the study, there was a total of 488 products in the ADC.

In the first part, the criteria used to identify LASA medicines were created according to the recommendations of the ISMP (figure 1 and table 1). ${ }^{920}$ The identified LASA medicines formed LASA groups that consisted of at least two different products. Medicinal products with the same generic or brand name were considered as LASA medicines if they had a different strength or package size. LASA groups containing at least one high-alert medication defined by ISMP or a high-alert medication list of HUS were identified (table 1 ). ${ }^{821}$

In the second part, an analysis of the inventory reports was performed to identify LASA medicines based on the active substances, generic names or brand names (figure 1). The ADC's inventory reports were available in alphabetical order for both generic names (in Finnish) and brand names. The identified LASA medicines were extracted to a table in the Microsoft Excel spreadsheet program alphabetically according to the active substances to form LASA groups (online supplemental table 1). Following this, products were identified by their Nordic article numbers.

\begin{tabular}{|c|c|c|c|}
\hline LASA risk & Data source & Criteria & Identification of high-alert medications* \\
\hline $\begin{array}{l}\text { Name of active substance or } \\
\text { generic name }\end{array}$ & $A D C$ inventory reports & $\begin{array}{l}\text { At least the first five (5) letters must be the same or 3-4 identical } \\
\text { letters and otherwise similar spelling } 20\end{array}$ & Yes \\
\hline Brand name & $A D C$ inventory reports & $\begin{array}{l}\text { At least the first five (5) letters must be the same or 3-4 identical } \\
\text { letters and otherwise similar spelling } 20\end{array}$ & Yes \\
\hline The appearance of the package & Visual observation & $\begin{array}{l}\text { In the same storage unit close to each other. At least the colouring or } \\
\text { size, or both, of the outer packaging look alike. If other LASA risks are } \\
\text { noted, the inner packaging was also acknowledged }\end{array}$ & Yes \\
\hline $\begin{array}{l}\text { Nordic article number or other } \\
\text { identification number }\end{array}$ & $A D C$ inventory reports & $\begin{array}{l}\text { Considered if there is at least one of the aforementioned LASA risks } \\
\text { and at least the first four (4) of the numbers are the same or the series } \\
\text { of numbers are otherwise similar }\end{array}$ & Yes \\
\hline
\end{tabular}

\footnotetext{
*Based on the ISMP ${ }^{8}$ and the HUS Helsinki University Hospital's intensive care units high-alert medication lists.

$A D C$, automated dispensing cabinet; LASA, look-alike, sound-alike.
} 
In the third part, safe storage of the identified LASA groups was evaluated (figure 1). ADC stock location reports were analysed to determine whether the products were properly stored apart, offering improvements where needed, or if there were other observations. If the LASA medicines were located close to each other in the same storage unit or with storage site numbers that could be easily confused (eg, 1 and 10), the placement was considered not safe. Other observations were made if the only option was to store LASA medicines in the same storage unit due to lack of space, but they were clearly separated from each other (eg, medicines located in the refrigerator).

In the fourth part, the ADC's storage units were inspected one by one and LASA medicines were observed according to the outer packaging (figure 1). The inner packages of LASA medicines identified in the first part and stored close to each other were examined. The inner packaging was also noted if the outer package was missing. The LASA medicines found according to the appearance of the packaging were photographed and listed (online supplemental figure 1). The study did not consider LASA medicines with a similar appearance if they were already safely stored in the ADC. Following this, LASA risks in the medicine search view of the cabinet were determined by visual observation and photographed as appropriate (online supplemental figure 1).

Last, an analysis of medication-use process from medicine prescribing to removing a product from an ADC was performed to evaluate possibilities for confusions (figure 1). We wanted to demonstrate what kind of LASA risks could contribute to errors in different process phases.

\section{RESULTS}

Approximately $70 \%(\mathrm{n}=355 / 488)$ of the ADCs medicine selection were associated with LASA risk with at least one other product (online supplemental table 1 and figure 1). Up to $20 \%(n=84 / 355)$ of the identified LASA medicines were highalert medications. The LASA groups by name contained 352 products, of which 81 were high-alert medications. The observational section included 30 products in total, including three LASA medicines that were not identified in the inventory report analysis (online supplemental figure 1). The number of identified LASA groups, including the amount of high-alert medication groups and the storage information, is presented in table 2 .

The size of the LASA groups varied from two different products to as many as 11 products (eg, paracetamol preparations). Over half $(n=105 / 175)$ of the LASA groups by name involved a LASA risk related to both generic and brand names (table 2). In addition, the same set of LASA groups included almost $90 \%$ $(n=17 / 19)$ of similar Nordic article number pairs. Examples of the identified LASA risks are presented in table 3. It was noted that some pharmaceutical manufacturers use look-alike packaging for medicines belonging to the same therapeutic class (figure 2) or also having LASA medicines by name (table 3).

A total of $16 \%(n=58 / 355)$ of the identified LASA medicines required placement correction due to LASA risk. This was approximately $12 \%(n=58 / 488)$ of the ADC's selection. Of the 15 LASA groups identified in the observational part of the study, six LASA groups were not found in the analysis of inventory reports, giving us a total of 181 LASA groups (table 2). Positively, over $80 \%(n=147 / 181)$ of LASA groups were stored safely apart from each other. Only eight groups including high-alert medications were unsafely stored. The ADC contained seven HUS Pharmacy-made $100 \mathrm{~mL}$ oral suspensions stored in the refrigerators. The suspensions are bottled into identical brown glass bottles and separated by different coloured labels. Two of them (hydrochlorothiazide $5 \mathrm{mg} / \mathrm{mL}$ and hydrocortisone $5 \mathrm{mg} / \mathrm{mL}$ ) were stored unsafely.

The analysis of the medication-use process revealed numerous steps where confusion can occur between similar names, packaging, medicine identification numbers and dosage forms (table 4). In particular, risks were observed if several LASA medicines were stored in the same storage unit. The features

\begin{tabular}{|c|c|c|c|}
\hline $\begin{array}{l}\text { LASA RISK } \\
\text { Inventory reports }\end{array}$ & $\begin{array}{l}\text { LASA groups involving high-alert } \\
\text { medications } \mathrm{n}(\%)\end{array}$ & $\begin{array}{l}\text { LASA groups not involving high- } \\
\text { alert medications } \mathrm{n}(\%)\end{array}$ & All LASA groups $\mathrm{n}(\%)$ \\
\hline Generic names & $18(38)$ & $37(29)$ & $55(31)$ \\
\hline - Nordic article number pairs* & $0(0)$ & $2(15)$ & $2(11)$ \\
\hline Brand names & 4 (8) & $11(9)$ & $15(9)$ \\
\hline -Nordic article number pairs* & $0(0)$ & $0(0)$ & $0(0)$ \\
\hline Generic and brand names & $26(54)$ & $79(62)$ & $105(60)$ \\
\hline -Nordic article number pairs* & $6(100)$ & $11(85)$ & $17(89)$ \\
\hline \multirow[t]{2}{*}{ Total } & $48(100)$ & $127(100)$ & $175(100)$ \\
\hline & $6(100)$ & $13(100)$ & $19(100)$ \\
\hline \multicolumn{4}{|l|}{$\begin{array}{l}\text { LASA risk } \\
\text { Visual observation }\end{array}$} \\
\hline Outer package & $1(17)$ & $2(22.2)$ & $3(20)$ \\
\hline Inner packaget & $3(50)$ & $4(44.4)$ & $7(47)$ \\
\hline Outer and inner package & $2(33)$ & $3(33.3)$ & $5(33)$ \\
\hline Total & $6(100)$ & $9(100)$ & $15(100)$ \\
\hline \multicolumn{4}{|l|}{ Storage } \\
\hline Storage was safe & $41(80)$ & $106(82)$ & $147(81.2)$ \\
\hline Storage was unsafe & $8(16)$ & $20(15)$ & $28(15.5)$ \\
\hline Observations with the storage & $2(4)$ & $4(3)$ & $6(3.3)$ \\
\hline Total & $51(100)$ & $130(100)$ & $181(100)$ \\
\hline
\end{tabular}

*Similar Nordic article numbers were observed from only the LASA groups identified by name and are already included in the total LASA group amount.

tSimilar inner packages were observed only based on the unsafely storage LASA groups identified by name. 


\begin{tabular}{ll}
\hline Table 3 Examples of identified LASA medicines and the associated risk of confusion \\
\hline LASA risk & Examples \\
\hline Name of active substance or generic name & When searching " $k$ ef" (in English equivalent to "cef"), the ADC suggests the following generic names and products, each \\
& on its own line: \\
& Kefotaksiimi (cefotaxime) Cefotaxim Eberth $0.5 \mathrm{G}$ \\
& Keftriaksoni (ceftriaxone) Ceftriaxon Fresenius Kabi $1 \mathrm{~g}$ and $2 \mathrm{~g}$ \\
& Products can be mixed with each other on the basis of the generic names (as well as brand names), all are antibiotics \\
& When searching "solu", the ADC suggests the following products by the brand name, each on its own line: \\
& Solu-Cortef $100 \mathrm{mg}$ and $250 \mathrm{mg}$ (hydrocortisone) \\
Brand name & Soluvit (water-soluble vitamins) \\
& Next to each other are Vitalipid Infant and Nutritrace, both infusion concentrates for nutritional support and high-alert \\
& medications*. Similar-sized white and purple package
\end{tabular}

${ }^{*}$ Based on the ISMP8 and the HUS Helsinki University Hospital's intensive care units high-alert medication lists.

$A D C$, automated dispensing cabinet; LASA, look-alike, sound-alike.

of the ADC can contribute risks, for example, in the case of a long generic or brand name, as the name does not fit completely on the small-sized screen when searching the product (online supplemental figure 1). Shortages of medicines and changes in the medication selection had contributed to situations where several products under different brand names, such as paracetamol preparations Pamol F $250 \mathrm{mg}$ and Pinex $250 \mathrm{mg}$, could be stored in the same storage site.

\section{DISCUSSION}

To the best of our knowledge, this is the first study to identify LASA medications combining both analysis of LASA generic and brand names with visual observation. In addition, we assessed the possible consequences of the identified LASA risks in the ADC during the different phases of the medication-use process. According to our findings, as much as $70 \%$ of the ADC's products were associated with LASA risk. Around $20 \%$ of the identified LASA drugs were also high-alert medications, when the consequences of the mix-ups can be particularly serious. The observed LASA risks were mix-ups between similar generic or brand names (or both), the identification numbers and the outer or inner packaging. One group of LASA medicines could include multiple risks (eg, similar names and outer packaging) which increases the risk of confusion. Although the ADCs are a part of prospective risk management with numerous safety features, human factors associated with LASA risks can still contribute medication errors.

LASA names have been studied, for example, by Lebanova et al (2012) and Shah et al (2016) examining orthographic and phonetic similarities. ${ }^{37}$ The results were conforming: the LASA medication pairs shared at least three letters, mostly situated in the prefix. In addition, LASA medicines have been identified

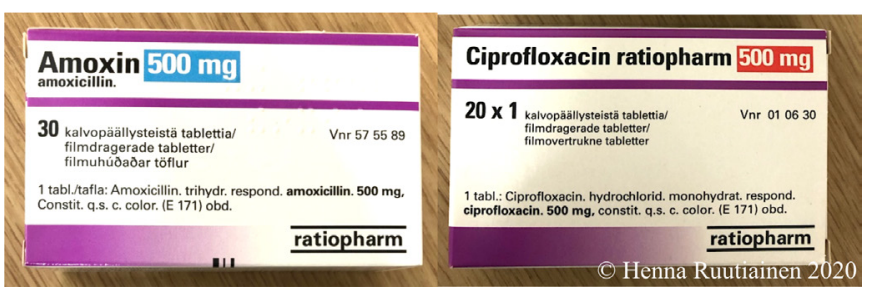

Figure 2 Similar outer packaging of antibiotic tablet preparations manufactured by Ratiopharm $\mathrm{GmbH}$. from incident reporting systems' reports. ${ }^{22}$ However, the diversity of incident reporting systems and the varying definition of LASA medicines in them have posed problems. As a solution, efforts have been made to develop a computer-assisted classification and recognition system to search for potential LASA medicines that could be used to prevent errors. ${ }^{31722}$ Electronic systems for recognising LASA medicines could also increase practitioners' LASA medicine knowledge. ${ }^{22}$

According to the guidelines of the ISMP, the LASA risk can be significantly reduced if at least the first five letters of the name are used when searching a medicine from an ADC. ${ }^{9}$ However, we found that despite the use of the first five letters, the LASA risk was present, especially with products that have an identical name. As one of the solutions is to prevent LASA risks, it has been recommended to use Tall Man lettering to emphasise the differences in the spelling of names by using capital letters (eg, tetraCAINE and tetraCOSACTIDE, DAUNOrubicin and DOXOrubicin). ${ }^{2}$ To the best of our knowledge, Tall Man letters are not commonly used on pharmaceutical industry labels in Europe. Nevertheless, it would be possible to use Tall Man lettering on the display of an ADC.

Although ADCs increase the safety of the medication-use process, they can contribute to oversights because of an excessive sense of safety. ${ }^{11}$ At the time of the study, medication order integration to the ADCs was not in place and overrides were used, and the medication dispenser should pay attention to a separate medication list. Integration of the patient's medicine profile to the ADC makes it possible to limit the variety of medicines that could be removed using overrides. ${ }^{23}$ The integration of the medicine profile does not eliminate prescribing errors related to LASA medicines, which is why ready-made electronic prescription templates and clinical decision support systems are recommended. ${ }^{57811-13172324}$ Barcodes should be used throughout the whole medication-use process to verify the right medicine. ${ }^{6} 8912$ In addition, pre-administration double-checks can be used, but the poor quality of these procedures can also cause medication errors, while especially mix-ups involving LASA medicines can easily be overlooked. 689132025

The main defence against the LASA risks when removing the medicine from the ADC is to carefully plan the sites where the medicines are stored. It is strongly recommended to store the LASA medicines in entirely different storage compartments if possible. ${ }^{891324}$ In this study, one storage compartment did not 
Table 4 Process description of LASA risks from prescription to removing the medicine from the automated dispensing cabinet (ADC)

\begin{tabular}{|c|c|c|}
\hline Process phase & Risks* & Examples of LASA risks \\
\hline & & $\begin{array}{l}\text { An epinephrine injection solution is needed at a strength of } 1 \mathrm{mg} / \mathrm{mL} \\
\text { (high-alert medication) }\end{array}$ \\
\hline Written or verbal prescription from a doctor & $\begin{array}{l}\text { Similar names: } \\
\text { Abbreviations are used } \\
\text { The verbal order is not repeated } \\
\text { The written order does not specify the intended } \\
\text { use } \\
\text { Inadvertently selecting a LASA medicine instead } \\
\text { of the desired medicine }\end{array}$ & $\begin{array}{l}\text { Hearing or reading the prescription incorrectly: Adrenaline } 1 \mathrm{mg} / \mathrm{mL} \text { is } \\
\text { confused with Lidocain c. adrenaline } 10 \mathrm{mg} / \mathrm{mL}+10 \mu \mathrm{g} / \mathrm{mL} \text {. The error is } \\
\text { facilitated if the indication is not known. }\end{array}$ \\
\hline $\begin{array}{l}\text { The product is searched from the ADC using the } \\
\text { generic name, brand name or identification number }\end{array}$ & $\begin{array}{l}\text { Similar names: } \\
\text { The medicine is searched using less than five } \\
\text { letters }\end{array}$ & $\begin{array}{l}\text { Searching a product using less than the first five letters, for example } \\
\text { "adre" } \rightarrow \text { the ADC offers seven different epinephrine products. }\end{array}$ \\
\hline $\begin{array}{l}\text { The product is selected and the dose is entered } \\
\text { Repeated if several medicines for the same patient } \\
\text { is needed }\end{array}$ & $\begin{array}{l}\text { The ADC contains several products with the } \\
\text { same name that become confused between } \\
\text { them }\end{array}$ & $\begin{array}{l}\text { Searching "adrenaliini" ("adrenalin") } \rightarrow \text { the ADC offers four different } \\
\text { epinephrine products. A high risk of choosing the wrong preparation, } \\
\text { for example, Adrenaline } 0.1 \mathrm{mg} / \mathrm{mL} \text { instead of Adrenaline } 1 \mathrm{mg} / \mathrm{mL} \text {, } \\
\text { Adrenaline } 0.1 \mathrm{mg} / \mathrm{mL}(5 \mathrm{~mL}) \text { and Noradrenaline Hospira } 1 \mathrm{mg} / \mathrm{mL}\end{array}$ \\
\hline & $\begin{array}{l}\text { Similar identification numbers or Nordic article } \\
\text { numbers }\end{array}$ & $\begin{array}{l}(4 \mathrm{~mL}) \text { (noradrenaline or norepinephrine). Can be confused with each } \\
\text { other as the products have a LASA risk caused by similar names and } \\
\text { Nordic article numbers } 536797 \text { and } 576786 \text {. }\end{array}$ \\
\hline $\begin{array}{l}\text { Guided by the } A D C \text {, the required amount of product } \\
\text { is removed from the package and the package is } \\
\text { put back in place }\end{array}$ & $\begin{array}{l}\text { Similar names or packaging: there are LASA } \\
\text { medicines in the same storage unit }\end{array}$ & 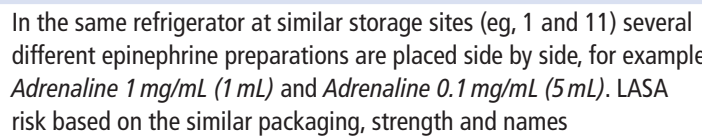 \\
\hline & & The outer package is missing $\rightarrow$ the ampoules look alike \\
\hline & & $\begin{array}{l}\text { Due to a change in the medication selection or due to a shortage of } \\
\text { medicines, the appearance or a brand name of the needed product } \\
\text { has changed } \rightarrow \text { higher risk to select a LASA medicine }\end{array}$ \\
\hline
\end{tabular}

${ }^{*}$ The table does not take a stand on other possible medication errors, such as misdiagnosis or dose calculation errors.

LASA, look-alike, sound-alike.

outperform the others in terms of the most significant LASA risk. If safe separate placement of LASA medicines is not possible, auxiliary labelling of LASA medicines and their storage compartments may be required in order to attract attention. ${ }^{7-9} 13$ The LASA risks should be considered, especially when restocking medicines to an ADC, when changing the medication selection, and preferably already when the medicine selection is being planned. ADCs can also be programmed with automated alerts regarding LASA risks, for example, when removing high-alert LASA medicine. ${ }^{8} 26$ Due to similar packaging, particular attention should be paid to pharmaceutical products compounded in hospital pharmacies. ${ }^{27}$

The study covered only one ADC at HUS and the ward's clinical specialty had an influence on the selection of medicines. The study was conducted at an intensive care unit, where the selection of medicines was large (488 products), but differed in characteristics, for example in terms of the fewer orally administered tablets and the diversity of intravenous products compared with other wards. However, we found it necessary to limit the research material because of the time-consuming research method. It is important that the identification of LASA medicines is performed on a ward-by-ward basis so that attention can be paid to these specific features. LASA medicine identification is especially important on wards that have patients requiring special attention (eg, paediatric departments and intensive care units). ${ }^{8} 28$ This feature was also considered in this study. The results can be applied when creating LASA medication lists and guidelines related to ADCs' inventory planning and safe use. Qualitative analysis of inventory reports and observation of storage sites were performed manually, so the possibility of errors leaving LASA medications unnoticed cannot be ruled out. However, the mixed-methods study was considered necessary, as there is limited research on the topic, and the study was intended to provide a preliminary overview of the issue.

Inventory reports were available in alphabetical order by either brand name or generic name. Therefore, content analysis could not be performed fully reliably to determine LASA medicine groups where the risk of confusions between different products was between the brand name and the generic name. In addition, the look-alike packages were only observed only when

\section{What this paper adds}

What is already known on this subject

- Look-alike, sound-alike (LASA) medicines have a high risk of confusion due to similar looking inner or outer packaging or similar sounding or looking generic name, brand name or identification number.

- Automated dispensing cabinets (ADCs) are ward-based, computer-controlled medicine storage and distribution systems, which have been shown to improve medication safety.

- The identification of LASA medicines and the specific features of the associated process risks in ADCs have not previously been studied.

What this study adds

- LASA risks occur by several factors (eg, similar names and look-alike packages) and one group of LASA medicines could include multiple LASA risks (eg, similar names and outer packaging).

- Consideration of all LASA risks requires the use of several different methods to identify LASA medicines. 
they were stored in the same storage compartment. Therefore, more products from the studied ADC could be considered as LASA medicines. However, LASA medicines were identified in several different ways by using largely different methods: a visual observation and a qualitative analysis of inventory reports based on the international list of LASA medicines. ${ }^{20}$ There are differences in literature if the products are LASA medicines only when the names resemble each other. If considered as aforementioned, the removal of the visual observation section would change the results for the better as all the founded LASA medicines were found to be stored unsafely. Furthermore, in literature, medical errors caused by confusions between similar strengths have been considered as LASA errors (eg, different concentrations of propofol). ${ }^{29}$ This study can be used as a basis for further research related to the topic and, for example, the characteristics of errors related to the identified LASA medicines or the level of harm caused by LASA medicine confusions could be studied.

\section{CONCLUSIONS}

Approximately $70 \%$ of the ADC's medication selection was identified as LASA medicines based on similar names or packaging. LASA medicines are a high-alert medication group of their own. In addition, around $20 \%$ of the recognised LASA medicines were identified as high-alert medications based on, for example, pharmacological properties. ADCs reduce the LASA risks when used correctly, but can also increase them, for instance, when placing multiple LASA medicines in the same storage compartment. Automation can also increase risk for errors due to a sense of security. It is important to promote the safe use of the ADCs and to raise awareness of LASA medications.

Funding The authors have not declared a specific grant for this research from any funding agency in the public, commercial or not-for-profit sectors.

Competing interests None declared.

Patient consent for publication Not required.

Ethics approval HUS Pharmacy granted research permission for this study. Ethics committee approval was not required because the study did not manage patient data.

Provenance and peer review Not commissioned; externally peer reviewed.

Data availability statement All data relevant to the study are included in the article or uploaded as online supplemental information.

Supplemental material This content has been supplied by the author(s). It has not been vetted by BMJ Publishing Group Limited (BMJ) and may not have been peer-reviewed. Any opinions or recommendations discussed are solely those of the author(s) and are not endorsed by BMJ. BMJ disclaims all liability and responsibility arising from any reliance placed on the content. Where the content includes any translated material, BMJ does not warrant the accuracy and reliability of the translations (including but not limited to local regulations, clinical guidelines, terminology, drug names and drug dosages), and is not responsible for any error and/or omissions arising from translation and adaptation or otherwise.

ORCID iD

Henna Karoliina Ruutiainen http://orcid.org/0000-0002-2184-3088

\section{REFERENCES}

1 World Health Organization. Medication without harm - WHO global patient safety challenge on medication safety. Geneva, Switzerland:WHO, 2017: 3-12. http://apps. who.int/iris/bitstream/10665/255263/1/WHOHIS-SDS- 2017.6-eng.pdf?ua=1\&ua=

2 The Institution of Safe Medication Practices (ISMP). Special edition: tall man lettering; ISMP updates its list of drug names with tall man letters, 2016. Available: www.ismp. org/resources/special-edition-tall-man-lettering-ismp-updates-its-list-drug-names-tallman-letters [Accessed 17 Mar 2020].
3 Shah MB, Merchant L, Chan IZ, et al. Characteristics that may help in the identification of potentially confusing proprietary drug names. Ther Innov Regul Sci 2017;51:232-6.

4 Billstein-Leber M, Carrillo CJD, Cassano AT, et al. ASHP guidelines on preventing medication errors in hospitals. Am J Health Syst Pharm 2018;75:1493-517.

5 Joint Commission International (JCI). Joint Commission International accreditation standards for hospitals. 7. Oak Brook, Illinois: Joint Commission Recourses, 2020.

6 Kuitunen S, Niittynen I, Airaksinen M, et al. Systemic causes of in-hospital intravenous medication errors: a systematic review. J Patient Saf 2020;0:1-9.

7 Lebanova HV, Getov IN, Grigorov EE. Descriptive study for look-alike and soundalike medicines based on local language peculiarities. Afr J Pharm Pharmacol 2012:6:2161-5.

8 The Institute for Safe Medication Practices (ISMP). List of high-alert medications in acute care settings, 2018. Available: www.ismp.org/sites/default/files/attachments/ 2018-08/highAlert2018-Acute-Final.pdf [Accessed 10 Mar 2020].

9 The Institute for Safe Medication Practices (ISMP). Guidelines for the safe use of automated dispensing cabinets. ISMP, 2019: 5-16.

10 National Coordinating Council for Medication Error Reporting and Prevention (NCC MERP). Recommendations for healthcare organizations to reduce medication errors associated with the label, labeling, and packaging of pharmaceutical (drug) products and related devices. NCC MERP, 2014. Available: www.nccmerp.org/ recommendations-health-care-organizations-reduce-medication-errors-associatedrelated-devices [Accessed 10 Mar 2020].

11 Ahtiainen HK, Kallio MM, Airaksinen M, et al. Safety, time and cost evaluation of automated and semi-automated drug distribution systems in hospitals: a systematic review. Eur J Hosp Pharm 2020;27:253-62.

12 Grissinger M. Safeguards for using and designing automated dispensing cabinets. PT 2012;37:490-530.

13 Berman A. Reducing medication errors through naming, labeling, and packaging. J Med Syst 2004;28:9-29.

14 Batson S, Herranz A, Rohrbach N, et al. Automation of in-hospital pharmacy dispensing: a systematic review. Eur J Hosp Pharm 2021;28:58-64.

15 Chapuis C, Bedouch P, Detavernier M, et al. Automated drug dispensing systems in the intensive care unit: a financial analysis. Crit Care 2015;19:1-5.

16 Austin JA, Smith IR, Tariq A. The impact of closed-loop electronic medication management on time to first dose: a comparative study between paper and digital Hospital environments. Int J Pharm Pract 2018;26:526-33.

17 Zacher JM, Cunningham FE, Zhao X, et al. Detection of potential look-alike/soundalike medication errors using Veterans Affairs administrative databases. Am J Health Syst Pharm 2018;75:1460-6.

18 Revised standards for quality improvement reporting excellence (SQUIRE 2.0). Available: http://www.equator-network.org/wp-content/uploads/2012/12/SQUIRE-2. 0-checklist.pdf [Accessed 15 Jun 2020].

19 Nordic Number Centre (NNC). Vnr: Nordic article number instruction booklet. Helsinki, Finland: Pharmaceutical Information Centre Ltd (PIC), 2019: 2. 6. https://wiki.vnr.fi/ wp-content/uploads/2019/02/Nordic-Article-Numbers-Nordic-instructions-ver-2.0.pdf

20 The Institution of Safe Medication Practices (ISMP). List of confused drug names. ISMP, 2019. Available: www.ismp.org/recommendations/confused-drug-names-list [Accessed 13 Jan 2020].

21 Schepel L, Lehtonen L, Airaksinen M, et al. How to identify organizational high-alert medications. J Patient Saf 2018. doi:10.1097/PTS.0000000000000512. [Epub ahead of print: 07 Jul 2018].

22 Wong ZSY. Statistical classification of drug incidents due to look-alike sound-alike mix-ups. Health Informatics I 2016;22:276-92.

23 The Institution of Safe Medication Practices (ISMP). ISMP targeted medication safety best practices for hospitals 2020-2021. ISMP, 2020. Available: www.ismp.org/sites/ default/files/attachments/2020-02/2020-2021 TMSBP- FINAL_1.pdf [Accessed 27 Jun 2020].

24 Bryan R, Aronson JK, Williams A, et al. The problem of look-alike, sound-alike name errors: drivers and solutions. Br J Clin Pharmacol 2020:1-9.

25 The Institution of Safe Medication Practices (ISMP). Independent double checks: worth the effort if used judiciously and properly. ISMP, 2019. Available: www.ismp.org/ resources/independent-double-checks-worth-effort-if-used-judiciously-and-properly [Accessed 5 Jul 2020].

26 Emmerton LM, Rizk MFS. Look-alike and sound-alike medicines: risks and 'solutions'. Int J Clin Pharm 2012:34:4-8.

27 Sauberan JB, Dean LM, Fiedelak J, et al. Origins of and solutions for neonatal medication-dispensing errors. Am J Health Syst Pharm 2010;67:49-57.

$28 \mathrm{McD}$ owell SE, Ferner HS, Ferner RE. The pathophysiology of medication errors: how and where they arise. Br J Clin Pharmacol 2009;67:605-13.

29 Tyynismaa L, Honkala A, Airaksinen M, et al. Identifying high-alert medications in a university hospital by applying data from the medication error reporting system. $J$ Patient Saf 2017. doi:10.1097/PTS.0000000000000388. [Epub ahead of print: 01 Jun 2017]. 